\title{
The Impact of Authorized Remanufacturing on Sustainable Remanufacturing
}

\author{
Xiqiang Xia ${ }^{1}$ (D) and Cuixia Zhang ${ }^{2, *}$ \\ 1 Business School, Zhengzhou University, Zhengzhou 450001, China; xqxia@zzu.edu.cn \\ 2 School of Mechanical and Electronic Engineering, Suzhou University, Suzhou 234000, China \\ * Correspondence: cuixiazhang@126.com
}

Received: 20 August 2019; Accepted: 23 September 2019; Published: 27 September 2019

\begin{abstract}
Remanufacturing could effectively solve resource shortage and environment crisis and achieve sustainable development of the economy. The original equipment manufacturer (OEM) could not only focus on its core business (i.e., producing new products), but also get profit from remanufacturing through the intellectual property rights. Based on the authorized remanufacturing, the game model between a manufacturer and a remanufacturer was constructed. Based on the game model, the impact of authorized remanufacturing on sustainable remanufacturing is analysed, and the coordination mechanism between manufacturer and remanufacturer is given. The main results are as follows: the OEM could increase its profit and change its unfavourable market competition status by authorizing remanufacturing; a franchise contract could make the sustainability supply chain optimized; when the ratio of the environment effect is greater than a certain threshold, centralized decision-making could not only increase the supply chain revenue, but also reduce the impact on the environment.
\end{abstract}

Keywords: remanufacturing; sustainability supply chain; authorized remanufacturing; game

\section{Introduction}

In the 21st century, with rapid economic development, the world is facing an increasingly serious shortage of resources as well as environmental problems, prompting all countries to alter the existing mode of economic development and look for a sustainable mode of economic development to achieve the recycling of resources and to minimize the adverse effect of products on the environment [1]. For the manufacturing industry, an effective way to achieve recycling economic development is remanufacturing; for instance, compared with new engines, remanufactured engines can not only reduce their environmental impact by $80 \%$ but also save on costs, energy, and raw materials by $50 \%$, $60 \%$, and $70 \%$, respectively [2].

However, because of the lack of remanufacturing infrastructure and expertise or the low marginal profitability of remanufactured products, original manufacturers are reluctant to engage in remanufacturing. As third-party remanufacturers engage in remanufacturing, the emergence of remanufactured products will result in reduced sales of new products in the market and reduced profits for the original manufacturer as well, which will prompt the original manufacturer to use intellectual property protection to limit the development of the remanufacturing industry. Meanwhile, none of the countries in the world will allow remanufacturers to infringe on intellectual property simply because remanufacturing is able to generate good economic and environmental benefits [3]. Authorized remanufacturing can ease the conflict between the original manufacturer and the remanufacturer so that the two can share the remanufacturing profit, manifesting plenty of successful cases in the remanufacturing industry. For example, the NCR (National Cash Register Company) Corporation of the United States paid $\$ 960,000$ to buy a remanufacture license from the Lemelson Medical and 
Educational Research Fund to legally engage in remanufacturing operations; IT companies such as Cisco allow independent third-party companies to remanufacture their used IT(Internet Technology) equipment and charge a license fee to the consumers who switch to buying the remanufactured products, which is essentially an authorized remanufacturing model [4]. Therefore, studying the impact of authorized remanufacturing on the manufacturing/remanufacturing supply chain is of great practical significance. Meanwhile, the comparison of the effects of decentralized decision-making and centralized decision-making under authorized remanufacturing on the remanufacturing supply chain can provide a scientific basis for the original manufacturers and remanufacturers making remanufacturing decision.

Currently, authorized remanufacturing has been seldom investigated. Zou et al. [5] compared the effects of authorized remanufacturing and outsourced remanufacturing on the manufacturing/remanufacturing supply chain and revealed under what conditions the original manufacturer should choose authorized remanufacturing. Zhu et al. [6] constructed a manufacturing/remanufacturing game model based on authorized remanufacturing to investigate the government subsidies strategy, and the results indicated that through remanufacturing, the original manufacturer could transfer not only remanufacturing proceeds but also government subsidies. Based on authorized remanufacturing, Xiong et al. [7,8] studied the original manufacturer's production decision-making and found that only when the remanufacturing saves more costs is the original manufacturer willing to engage in remanufacturing by authorizing a third party to remanufacture; further, by comparing the impacts of two methods of authorized remanufacturing (authorizing a retailer to remanufacture vs. authorizing a third-party to remanufacture) on the profits of manufacturing/remanufacturing supply chain members, they found that authorizing a third-party remanufacturer is more beneficial to the original manufacturer. Based on a network model, Li [9] analyzed the pattern of the effect of authorized remanufacturing on the closed-loop supply chain of remanufacturing. Wang [10] studied the optimal decision of the closed-loop supply chain under authorized remanufacturing based on the optimization model.

Contract analysis has received considerable attention in supply chain literature. Lind et al. [11] through several case studies of European firms, discuss various inter-organizational relationships that remanufacturers maintain, among their key finding is a new relationship called "raman-contracts" where the OEM (Original Equipment Manufacturer) collaborates with the remanufacturing activities. Matsumoto et al. [12] studies the remanufacturing practices of firms in Japan, through case studies of eleven remanufacturers, the authors attempt to determine the motives behind remanufacturing and identify several factors such as economic benefits, environmental benefits, and quality control among others. Kaya [13] discusses a linear contract with transfer payments to coordinate a remanufacturing based channel. Govindan et al. [14] discuss the case of coordination of a reverse supply chain using revenue sharing contracts. Yalabik et al. [15] build on the above to develop an economic model of remanufacturing with the assumption of lease contracting.

Although the existing studies have made great achievements, there are still some issues to be addressed. For examples, Zhu et al. [6] studied only the government subsidies under authorized remanufacturing but neglected the coordination strategy of the supply chain under authorized remanufacturing; Xiong et al. [7,8] addressed the choice of authorized remanufacturing strategies and supply chain coordination but lacked the analyses on the effects of decentralized decision-making and centralized decision-making on consumer surplus, social surplus, and the environment; although the effect of authorized remanufacturing on the remanufacturing supply chain has been examined, the coordination mechanism has not been addressed $[5,9,10]$. The remanufacturing contract of supply chain is studied, such as [11-15]. Therefore, in this study, a game model of manufacturing/remanufacturing was constructed based on authorized remanufacturing to compare the effects of decentralized decision-making and centralized decision-making on the competition and coordination mechanisms of the manufacturing/remanufacturing supply chain, to provide a scientific basis for the decision-making of original manufacturers and remanufacturers. 
This paper contains five sections. In Section 1, the research background and literature review are given; in Section 2, the model is described; in Section 3, the model solution is presented; in Section 4, the model analysis is performed; and in Section 5, conclusions are drawn.

\section{Model}

\subsection{Description of the Problem}

In reference to the literature [5,6], a single cycle game model comprising an original manufacturer and a remanufacturer is constructed to study the mechanism of the impact of authorized remanufacturing on manufacturing/remanufacturing supply chain competition, based on which the effects of centralized decision-making and decentralized decision-making on manufacturing/remanufacturing supply chain are compared, and the supply chain coordination mechanism is further investigated. In the case of decentralized decision-making, the original manufacturer is responsible only for producing new products, and at the same time, the original manufacturer charges the remanufacturer the patent fees for the remanufactured products through the protection of intellectual property (called the authorized remanufacturing expense in this study), the decision-making variables of which are the retail price per new product unit and the licensing fee of the remanufactured product. The remanufacturer is responsible for the production of the remanufactured product; however, it needs to pay the original manufacturer a certain licensing fee per unit of remanufactured product for the remanufacturing rights, whose decision-making variable is the recycling rate of the used product.

In the case of decentralized decision-making, the sequence of the decision-making model is as follows. First, the original manufacturer makes a decision on the licensing fee on the basis of the remanufactured product and the retail price per new product unit, and then the remanufacturer makes a decision on the recycling rate of the used product. According to Stackelberg's inverse solution, the remanufacturer determines the recycling rate of the used product, and then the original manufacturer determines the retail price per new product unit and the licensing fee on the basis of the remanufactured product.

\subsection{Model Function}

\subsubsection{Model Demand Function}

In reference to the literature [16,17], let the consumer's willingness to pay (WTP) for the product be $\theta$, and $\theta$ obeys the uniform distribution of $[0,1]$, i.e., $f(\theta) \sim[0,1]$. Let the retail price per remanufactured product unit relative to the consumer's lowest accepted price (referred to as discount price in this study) of the retail price per new product unit be $\delta$; then, the consumer surplus of the consumer purchasing the new product is $U_{n}=\theta-p_{n}$, and that of the consumer purchasing the remanufactured product is $U_{r}=\delta \theta-p_{r}$. Only when the consumer surplus of the consumer purchasing a new product unit is greater than that of the consumer purchasing a remanufactured product unit, i.e., $U_{n}>U_{r}$, is the consumer willing to purchase the new product, and the WTP range of the new product is $\Theta_{n}=\left\{\theta: U_{n}>\max \left\{U_{r}, 0\right\}\right\}$. Similarly, the WTP range of the remanufactured product is $\Theta_{r}=\left\{\theta: U_{r}>\max \left\{U_{n}, 0\right\}\right\}$. Further, the market demand for the new products and remanufactured products are, respectively, as follows:

$$
q_{n}^{i}=\int_{\theta \in \Theta_{n}} f(\theta) \mathrm{d} \theta=\frac{1-\delta-p_{n}^{i}+p_{r}^{i}}{1-\delta}, q_{r}^{i}=\int_{\theta \in \Theta_{r}} f(\theta) \mathrm{d} \theta=\frac{\delta p_{n}^{i}-p_{r}^{i}}{\delta(1-\delta)}
$$

Ultimately, we obtain:

$$
p_{n}^{i}=1-q_{n}^{i}-\delta q_{r}^{i}, p_{r}^{i}=\delta\left(1-q_{n}^{i}-q_{r}^{i}\right), i \in\{D, C, F\}
$$




\subsubsection{Model Recycling Function}

According to the literature [18], the costs of recycling the used product increase with the amount of the used product in the manner of a convex function. Without loss of generality, the cost function of previous related studies, i.e., $k\left(\tau^{i} q_{n}^{i}\right)^{2}$, is used here. Wherein, $\tau$ is the recycling rate, $k$ is the ratio parameter, and $i \in\{D, C, F\}$.

\section{Model Solution}

In the case of decentralized decision-making, the profit functions of the original manufacturer and the remanufacturer are, respectively, as follows:

$$
\begin{aligned}
\pi_{n}^{D}= & \left(p_{n}^{D}-c\right) q_{n}^{D}+z q_{r}^{D}=\left(1-q_{n}^{D}-\delta q_{r}^{D}-c\right) q_{n}^{D}+z q_{r}^{D} \\
\pi_{r}^{D} & =\left(p_{r}^{D}-c+s-z\right) q_{r}^{D}-k\left(\tau^{D} q_{n}^{D}\right)^{2} \\
& =\left[\delta\left(1-q_{n}^{D}-q_{r}^{D}\right)-c+s-z\right] q_{r}^{D}-k\left(\tau^{D} q_{n}^{D}\right)^{2}
\end{aligned}
$$

in which, $\left(p_{n}^{D}-c\right) q_{n}^{D}$ and $z q_{r}^{D}$ respectively, represent the profit from the sale of the new product and the profit through authorizing remanufacturing, and $\left(p_{r}^{D}-c+s-z\right) q_{r}^{D}$ represents the remanufacturer's profit from the sale of the remanufactured product under the authorization of remanufacturing, while $k\left(\tau^{D} q_{n}^{D}\right)^{2}$ represents the costs of recycling the used product.

In the case of centralized decision-making, the profit function of the manufacturing/remanufacturing supply chain is as follows:

$$
\pi^{C}=\left(p_{n}^{C}-c\right) q_{n}^{C}+\left(p_{r}^{C}-c+s\right) q_{r}^{C}-k\left(\tau^{C} q_{n}^{C}\right)^{2}
$$

Conclusion 1. (a) with respect to the recycling rate of the used product $\left(\tau^{D}\right)$, Formula (2) is a concave function, and by integrating the recycling rate obtained from Formula (2) into Formula (1), Formula (1) becomes a concave function with respect to $q_{n}^{D}, z$; (b) with respect to $q_{n}^{C}, q_{r}^{C}$, Formula (3) is a concave function.

Proof. (a) by integrating $q_{r}^{D}=\tau q_{n}^{D}$ into Formula (2), then we obtain:

$$
\pi_{r}^{D}=\left[\delta\left(1-q_{n}^{D}-\tau^{D} q_{n}^{D}\right)-c+s-z\right] \tau^{D} q_{n}^{D}-k\left(\tau^{D} q_{n}^{D}\right)^{2}
$$

By taking the first and second order partial derivatives on $\pi_{r}^{D}$ with respect to $\tau^{D}$, we obtain:

$$
\begin{gathered}
\frac{\partial \pi_{r}^{D}}{\partial \tau^{D}}=\left[\delta\left(1-q_{n}^{D}-2 \tau^{D} q_{n}^{D}\right)-c+s-z\right] q_{n}^{D}-2 k \tau^{D} q_{n}^{D 2} \\
\frac{\partial^{2} \pi_{r}^{D}}{\partial \tau^{D 2}}=-2(\delta+k) q_{n}^{D 2}
\end{gathered}
$$

From $\frac{\partial^{2} \pi_{r}^{D}}{\partial \tau^{D 2}}=-2(\delta+k) q_{n}^{D 2}<0$, it indicates that Formula (2) is a concave function with respect to the recycling rate of the used product $\left(\tau^{D}\right)$.

By integrating $q_{r}^{D}=\tau^{D} q_{n}^{D}$ and $\tau^{D *}=\frac{\delta-c+s-z-\delta q_{n}^{D}}{2(\delta+k) q_{n}^{D}}$ into Formula (2), we obtain:

$$
\pi_{n}^{D}=\left(1-q_{n}^{D}-\delta \frac{\delta-c+s-z-\delta q_{n}^{D}}{2(\delta+k)}-c\right) q_{n}^{D}+z \frac{\delta-c+s-z-\delta q_{n}^{D}}{2(\delta+k)}
$$

By taking the first and second order partial derivatives on Formula (6) with respect to $q_{n}^{D}, w^{D}$, we obtain:

$$
\frac{\partial \pi_{n}^{D}}{\partial q_{n}^{D}}=1-\frac{(2-\delta) \delta+2 k}{\delta+k} q_{n}^{D}-\delta \frac{\delta-c+s}{2(\delta+k)}
$$




$$
\begin{gathered}
\frac{\partial \pi_{n}^{D}}{\partial z}=\frac{\delta-c+s}{2(\delta+k)}-\frac{z}{\delta+k} \\
\frac{\partial^{2} \pi_{n}^{D}}{\partial q_{n}^{D 2}}=-\frac{(2-\delta) \delta+2 k}{\delta+k}, \frac{\partial^{2} \pi_{n}^{D}}{\partial q_{n}^{D} \partial w^{D}}=0, \frac{\partial \pi_{n}^{D}}{\partial w^{D} \partial q_{n}^{D}}=0, \frac{\partial^{2} \pi_{n}^{D}}{\partial w^{D 2}}=-\frac{1}{\delta+k^{\prime}}
\end{gathered}
$$

The second-order Hessian matrix of Formula (6) with respect to $q_{n}^{D}, w^{D}$ is:

$$
H=\left[\begin{array}{cc}
-\frac{(2-\delta) \delta+2 k}{\delta+k} & 0 \\
0 & -\frac{1}{\delta+k}
\end{array}\right]
$$

The diagonal elements of the Hessian matrix are negative, and $|H|=\left|\begin{array}{cc}-\frac{(2-\delta) \delta+2 k}{\delta+k} & 0 \\ 0 & -\frac{1}{\delta+k}\end{array}\right|=$ $\frac{(2-\delta) \delta+2 k}{(\delta+k)^{2}}>0$, indicating that Formula (6) is a concave function with respect to $q_{n}^{D}, z$, i.e., Formula (1) is a concave function with respect to $q_{n}^{D}, z$.

Similarly, the proof of (b) can be established. From Conclusion 1, Conclusion 2 can be drawn.

Conclusion 2. Under both decision-making models, the Nash equilibrium solutions of the unit retail prices, the sales volumes, the sales profits of the new product and the remanufactured product, the unit outsourcing cost of the remanufactured product, and the recycling rate of the used product are shown as Table 1.

Table 1. Optimal equilibrium solutions under different decision models.

\begin{tabular}{ccc}
\hline & $D$ & $C$ \\
\hline$p_{n}^{i *}$ & $\frac{1+c}{2}$ & $\frac{1+c}{2}$ \\
$p_{r}^{i *}$ & $\delta\left[\frac{1}{2}+\frac{(1+2 k-\delta) c-(1-\delta) s}{2\left(\delta+2 k-\delta^{2}\right)}\right]$ & $\delta\left[\frac{1}{2}+\frac{(1+k-\delta) c-(1-\delta) s}{2\left(\delta+k-\delta^{2}\right)}\right]$ \\
$q_{n}^{i *}$ & $\frac{1}{2}-\frac{2 k c+\delta(c+s)}{2\left(2 \delta+2 k-\delta^{2}\right)}$ & $\frac{1}{2}-\frac{k c+\delta s}{2\left(\delta+k-\delta^{2}\right)}$ \\
$q_{r}^{i *}$ & $\frac{\delta c-c+s}{2\left(2 \delta+2 k-\delta^{2}\right)}$ & $\frac{\delta c-c+s}{2\left(\delta+k-\delta^{2}\right)}$ \\
$\pi_{n}^{i *}$ & $\frac{(1-c)^{2}}{4}+\frac{(\delta c-c+s)^{2}}{4\left(2 \delta+2 k-\delta^{2}\right)}$ & - \\
$\pi_{r}^{i *}$ & $\frac{(\delta+k)(\delta c-c+s)^{2}}{4\left(2 \delta+2 k-\delta^{2}\right)^{2}}$ & - \\
$\pi_{C}^{*}$ & - & $\frac{(1-c)^{2}}{4}+\frac{(\delta c-c+s)^{2}}{4\left(\delta+k-\delta^{2}\right)}$ \\
$z^{*}$ & $\frac{\delta-c+s}{2}$ & - \\
$\tau^{i *}$ & $\frac{\delta c+s-c}{2 \delta+2 k-\delta^{2}-2 k c-\delta(c+s)}$ & $\frac{\delta c+s-c}{\delta+k-\delta^{2}-c k-\delta s}$ \\
\hline
\end{tabular}

\section{Model Analysis}

Based on Conclusion 2, Conclusions 3 and 4 are drawn.

Conclusion 3. (I) $q_{n}^{*}>q_{n}^{D *}, q_{n}^{*}>q_{n}^{C *}$; (II) $\pi_{n}^{D *}>\pi_{n}^{*}$.

Proof. When there is no remanufacturing in the market, the original manufacturer's decision function is

$$
\pi_{n}=\left(p_{n}-c\right) q_{n}=\left(1-q_{n}-c\right) q_{n}
$$

Similar to those of Conclusion 2, we can obtain the optimal Nash equilibrium solutions for Formula (7) as follows:

$$
p_{n}^{*}=\frac{1+c}{2}, q_{n}^{*}=\frac{1-c}{2}, \pi_{n}^{*}=\frac{(1-c)^{2}}{4}
$$

From Table 1, we have

$$
q_{n}^{*}-q_{n}^{D *}=\frac{\delta(\delta c-c+s)}{2\left(2 \delta+2 k-\delta^{2}\right)}>0
$$




$$
q_{n}^{*}-q_{n}^{C *}=\frac{\delta(\delta c+s-c)}{2\left(\delta+k-\delta^{2}\right)}>0
$$

Therefore, $q_{n}^{*}>q_{n}^{D *}, q_{n}^{*}>q_{n}^{C *}$.

Under authorized remanufacturing, the original manufacturer's profit is $\pi_{n}^{D *}=\frac{(1-c)^{2}}{4}+\frac{(\delta c-c+s)^{2}}{4\left(2 \delta+2 k-\delta^{2}\right)^{2}}$, thus $\pi_{n}^{D *}-\pi_{n}^{*}=\frac{(\delta c-c+s)^{2}}{4\left(2 \delta+2 k-\delta^{2}\right)}>0$, i.e., $\pi_{n}^{D *}>\pi_{n}^{*}$.

Conclusion 3 shows that when the original manufacturer does not authorize remanufacturing, the remanufactured product would reduce not only the sales of the new product but also the profitability of the original manufacturer, i.e., the emergence of remanufacturing would be detrimental to the original manufacturer. However, when the original manufacturer adopts the authorized remanufacturing, although the sales volume of the new product is reduced and the sales revenue of the new product is also reduced, through authorizing remanufacturing, the original manufacturer can benefit by transferring remanufacturing and, due to the transferred remanufacturing benefit, is greater than the revenue reduction caused by the reduced sales of the new product; ultimately, the original manufacturer's revenue increases, i.e., by adopting authorized remanufacturing, it is possible to change the original manufacturer's unfavourable competitive status.

Conclusion 4. The cost savings made on the remanufactured product unit affects the Nash Equilibrium solutions:

$$
\begin{gathered}
\text { (I) } \frac{\partial p_{n}^{D *}}{\partial s}=\frac{\partial p_{n}^{C *}}{\partial s}=0, \frac{\partial p_{r}^{D *}}{\partial s}<0, \frac{\partial p_{r}^{C *}}{\partial s}<0 ; \\
\text { (II) } \frac{\partial q_{n}^{D *}}{\partial s}=\frac{\partial q_{n}^{C *}}{\partial s}<0, \frac{\partial q_{r}^{D *}}{\partial s}>0, \frac{\partial q_{r}^{C *}}{\partial s}>0 ; \\
\text { (III) } \frac{\partial \tau^{D *}}{\partial s}>0, \frac{\partial \tau^{C *}}{\partial s}>0 ; \\
\text { (IV) } \frac{\partial z^{*}}{\partial s}<0 ; \\
\text { (V) } \frac{\partial \pi_{n}^{D *}}{\partial s}>0, \frac{\partial \pi_{r}^{D *}}{\partial s}>0, \frac{\partial \pi^{C *}}{\partial s}>0 .
\end{gathered}
$$

Proof. Table 1 shows that

$$
\frac{\partial p_{n}^{D *}}{\partial s}=\frac{\partial p_{n}^{C *}}{\partial s}=0, \frac{\partial p_{r}^{D *}}{\partial s}=-\frac{\delta(1-\delta) s}{2\left(\delta+2 k-\delta^{2}\right)}<0
$$

i.e.,

$$
\frac{\partial p_{r}^{C *}}{\partial s}=-\frac{\delta(1-\delta) s}{2\left(\delta+k-\delta^{2}\right)}<0
$$

(a) is valid; similarly, the validities of other conclusions can be established. Therefore, Conclusion 4 is proven.

According to the literature $[19,20]$, when the original manufacturer does not adopt authorized remanufacturing, the original manufacturer's profit is negatively correlated with the cost saving made on the remanufactured product, i.e., the greater the cost savings made on the unit remanufactured product, the smaller is the profit of the original manufacturer. However, when the original manufacturer adopts authorized remanufacturing, although the sales volume of the new product is negatively correlated with the cost savings made on the remanufactured product unit, its revenue is positively correlated with the cost savings made on the remanufactured product unit, i.e., the greater the cost savings made on the remanufactured product unit, the greater is the revenue the original manufacturer generates. Therefore, the original manufacturer should strive to reduce the cost savings made on 
the remanufactured product; for example, in the initial stage of product design, dismantlability and remanufacture ability should be taken into account.

Conclusion 5. $\pi_{C}^{*}>\pi_{n}^{D *}+\pi_{r}^{D *}$, i.e., in the case of decentralized decision-making, the marginal loss will affect the supply chain, making its return lower than that in the case of centralized decision-making.

The proof of Conclusion 5 is similar to that of Conclusion 3 and hereby omitted.

Conclusion 5 shows that in the case of decentralized decision-making, a "marginal effect" will arise, lowering the revenue of the remanufacturing supply chain. Therefore, it is necessary to investigate the coordination contract of the remanufacturing supply chain in the case of decentralized decision-making so that the profit of the remanufacturing supply chain in the case of decentralized decision-making is not less than that in the case of centralized decision-making. Next, based on the franchise contract, the coordination contract is presented.

\subsection{Franchise Contract}

A franchise contract mainly refers to authorization by the original manufacturer to remanufacturers to remanufacture by charging a licensing fee $(z)$ on the basis of the remanufactured product unit and to coordinate the remanufacturing supply chain, and $z$ is generally smaller than $z^{D}$, so the production cost of the remanufactured product is reduced, and thus, the sales of the remanufactured product are promoted. However, in this case, the remanufacturer must first pay a fee $(F)$ to the original manufacturer. Assuming the terms that the remanufacturer provides for the original manufacturer is $(z, F)$, i.e., remanufacturing can generate a lower license fee per remanufactured product unit, but the remanufacturer needs to pay a fixed fee $(F)$ as a profit share, then the original manufacturer considers whether to accept the contract; if it accepts the contract, then the manufacturer makes the optimal decision on the contract. Based on the above ideas, we can have the following decision model.

The profit functions of the original manufacturer and the remanufacturer are, respectively, as follows:

$$
\begin{aligned}
\pi_{n}^{f}= & \left(1-q_{n}^{f}-\delta q_{r}^{f}-c\right) q_{n}^{f}+z^{f} q_{r}^{f}+F \\
\pi_{r}^{f}= & \left(\delta-\delta q_{n}^{f}-\delta q_{r}^{f}-c-z^{f}+s\right) q_{r}^{f} \\
& -k\left(\tau^{f} q_{n}^{f}\right)^{2}-F
\end{aligned}
$$

From Formulas (8) and (9), we obtain the decision models of the original manufacturer and the remanufacturer, respectively, as follows:

$$
\begin{aligned}
\max \pi_{r}^{f}= & \left(\delta-\delta q_{n}^{f}-\delta q_{r}^{f}-c-z^{f}+s\right) q_{r}^{f} \\
& -k\left(\tau^{f} q_{n}^{f}\right)^{2}-F
\end{aligned}
$$

s.t.

$$
q_{n}^{f}, z^{f} \in \underset{\pi_{n}^{f *} \geq \pi_{n}^{D *}}{\operatorname{argmax}} \pi_{n}^{f}=\left(1-q_{n}^{f}-\delta q_{r}^{f}-c\right) q_{n}^{f}+z^{f} q_{r}^{f}+F
$$

By solving the above models, we have:

$$
\begin{gathered}
\tau^{f *}=\frac{\delta c+s-c}{\delta+k-\delta^{2}-c k-\delta s}, p_{n}^{f *}=\frac{1+c}{2}, p_{r}^{f *}=\delta\left[\frac{1}{2}+\frac{(1+k-\delta) c-(1-\delta) s}{2\left(\delta+k-\delta^{2}\right)}\right] \\
q_{n}^{f *}=\frac{1}{2}-\frac{k c+\delta s}{2\left(\delta+k-\delta^{2}\right)}, q_{r}^{f *}=\frac{\delta c-c+s}{2\left(\delta+k-\delta^{2}\right)}, z^{f *}=\frac{\delta^{2}(1-\delta-s)+\delta k(1-c)}{2\left(\delta+k-\delta^{2}\right)} \\
F^{*}=\frac{\delta(1-\delta)(1-c)^{2}}{4\left(\delta+k-\delta^{2}\right)}+\frac{(\delta c-c+s)^{2}}{4\left(2 \delta+2 k-\delta^{2}\right)}-\delta \frac{(1-c)(1-\delta-s)}{4\left(\delta+k-\delta^{2}\right)}-\delta \frac{[1-\delta-s+k(1-c)](\delta c-c+s)}{4\left(\delta+k-\delta^{2}\right)^{2}}
\end{gathered}
$$




$$
\begin{gathered}
\pi_{n}^{f *}=\pi_{n}^{D *}=\frac{(1-c)^{2}}{4}+\frac{(\delta c-c+s)^{2}}{4\left(2 \delta+2 k-\delta^{2}\right)^{2}}, \\
\pi_{r}^{f *}=\pi^{C *}-\pi_{n}^{f *}=\pi^{C *}-\pi_{n}^{D *}
\end{gathered}
$$

The coordination contract of the supply chain is thus obtained.

Conclusion 6. The remanufacturer's adoption of the franchise contract can cause the supply chain to achieve coordination.

Proof. Based on the results obtained by the above solutions, we have:

$$
\pi_{r}^{f *}+\pi_{n}^{f *}=\pi_{r}^{f *}+\pi_{n}^{D *}=\pi^{C *}
$$

According to Formula (12), it shows the supply chain has achieved coordination.

\subsection{The Effects of Two Decision Models on Consumer Surplus and Social Surplus}

The consumer surpluses in the cases of decentralized decision-making and centralized decision-making are:

$$
\begin{aligned}
S^{D} & =\frac{\left(q_{n}^{D *}+\delta q_{r}^{D *}\right)^{2}+\delta(1-\delta) q_{r}^{D *}}{2} \\
S^{C} & =\frac{\left(q_{n}^{C *}+\delta q_{r}^{C *}\right)^{2}+\delta(1-\delta) q_{r}^{C *}}{2}
\end{aligned}
$$

Social surpluses in the cases of decentralized decision-making and centralized decision-making are:

$$
\begin{gathered}
S^{C D}=S^{D}+\pi_{n}^{D *}+\pi_{r}^{D *} \\
S^{C C}=S^{C}+\pi_{C}^{*}
\end{gathered}
$$

According to Table 1 and Formulas (13)-(16), Conclusion 5 can be obtained.

Conclusion 7. The effects of the two decision-making models on consumer surplus and social surplus are $S^{C}>S^{D}, S^{C C}>S^{D C}$.

Proof. From Table 1 and Formulas (13) and (14), we have:

$$
\begin{aligned}
& S^{D}=\frac{(1-c)^{2}}{8}+\frac{\delta(1-\delta)(\delta c-c+s)}{4\left(2 \delta+2 k-\delta^{2}\right)} \\
& S^{C}=\frac{(1-c)^{2}}{8}+\frac{\delta(1-\delta)(\delta c-c+s)}{4\left(\delta+k-\delta^{2}\right)}
\end{aligned}
$$

Thus,

$$
S^{D}-S^{C}=-\frac{\delta(1-\delta)(\delta+k)(\delta c-c+s)}{4\left(\delta+k-\delta^{2}\right)\left(2 \delta+2 k-\delta^{2}\right)}<0
$$

i.e., $S^{C}>S^{D}$.

Then, based on Conclusion 4, we have $\pi_{C}^{*}>\pi_{n}^{D *}+\pi_{r}^{D *}$, thus

$$
S^{C C}=S^{C}+\pi_{C}^{*}>S^{C D}=S^{D}+\pi_{n}^{D *}+\pi_{r}^{D *}
$$

i.e., $S^{C C}>S^{D C}$. 
Conclusion 7 shows that based on Table 1, in the case of centralized decision-making, although the unit retail prices of the two products are reduced and due to the competition in the market, the sales of the new product decrease while those of the remanufactured products increase, while the consumer surplus and social surplus resulting from the increase of the remanufactured product are greater than those resulting from the decrease of the new product, ultimately leading to increased consumer surplus and social surplus in the case of centralized decision-making, i.e., in the case of centralized decision-making, the remanufactured product significantly increases the consumer surplus and social surplus. Therefore, the emergence of the remanufactured product is conducive not only to environmental protection but also to increasing the consumer surplus and social surplus.

\subsection{Effects of Decentralized Decision-Making and Centralized Decision-Making on the Environment}

For the sake of discussion, let

$$
e^{D}=e_{n} q_{n}^{D *}+e_{r} q_{r}^{D *}, e^{C}=e_{n} q_{n}^{C *}+e_{r} q_{r}^{C *}
$$

Based on Table 1, we have:

$$
\begin{aligned}
& e^{D}=e_{n} q_{n}^{D *}+e_{r} q_{r}^{D *} \\
& =\frac{e_{n}}{2}-\frac{2 k c+\delta(c+s)}{2\left(2 \delta+2 k-\delta^{2}\right)} e_{n} \\
& +\frac{\delta c-c+s}{2\left(2 \delta+2 k-\delta^{2}\right)} e_{r} \\
& e^{C}=e_{n} q_{n}^{C *}+e_{r} q_{r}^{C *} \\
& =\frac{e_{n}}{2}-\frac{k c+\delta s}{2\left(\delta+k-\delta^{2}\right)} e_{n} \\
& +\frac{\delta c-c+s}{2\left(\delta+k-\delta^{2}\right)} e_{r}
\end{aligned}
$$

Based on Formulas (17) and (18), we can draw Conclusion 8.

Conclusion 8. The effects of two decision-making models on the environment are as follows:

(1) When $\frac{e_{r}}{e_{n}}>\delta$, in the case of centralized decision-making, the supply chain has a greater impact on the environment, i.e., centralized decision-making reduces the "marginal effect" of the supply chain, but it is not conducive to environmental protection;

(2) When $\frac{e_{r}}{e_{n}}<\delta$, in the case of decentralized decision-making, the supply chain has a greater impact on the environment, i.e., centralized decision-making not only can effectively increase the profit of the supply chain but also can reduce the impact on the environment;

(3) When $\frac{e_{r}}{e_{n}}=\delta$, the environmental impacts in the cases of centralized decision-making and decentralized decision-making are identical; however, centralized decision-making can effectively increase the profit of the supply chain.

Proof. From Formulas (17) and (18), we have:

$$
e^{C}-e^{D}=\frac{(\delta+k)(\delta c+s-c)\left(e_{r}-\delta e_{n}\right)}{2\left(\delta+k-\delta^{2}\right)\left(2 \delta+2 k-\delta^{2}\right)}
$$

According to Formula (19), when $\frac{e_{r}}{e_{n}}>\delta, e^{C}>e^{D}$;

If $\frac{e_{r}}{e_{n}}<\delta$, then $e^{C}<e^{D}$;

If $\frac{e_{r}}{e_{n}}=\delta$, then $e^{C}=e^{D}$.

With the literature [21,22], Conclusion 8 shows that when the ratio of the environmental impact of the unit remanufactured product and that of the unit new product is equal to or less than a certain threshold, centralized decision-making is not only conducive to the revenue increase of the supply chain but also effectively reduces the environmental impact of the two products; in this case, the supply chain must be coordinated, and if the original manufacturer is unwilling to cooperate, the government 
needs to introduce relevant laws and regulations to encourage the development of the remanufacturing industry, while asking the original manufacturer to fulfil its corporate social responsibilities.

\section{Conclusions}

In this study, we constructed a manufacturing/remanufacturing game model to investigate the effect of authorized remanufacturing on the competition mechanism of the manufacturing/remanufacturing supply chain and its coordination mechanism. Based on this model, the influences of authorized remanufacturing on the sales profit, consumer surplus, social surplus and environment were studied under decentralized decision-making and centralized decision-making, and at the same time, based on a franchise contract, the coordination mechanism of the manufacturing/remanufacturing supply chain was investigated to realize the supply chain coordination.

This paper's main contributions are summarized as follows: Firstly, the impact of authorizing remanufacturing on remanufacturing is analysed. The OEM could increase its profit and change its unfavourable market competition position through authorizing remanufacturing. And, the OEM's profit is positive correlation to cost saving of remanufacturing. Thus, The OEM should strive to increase the cost saving of remanufacturing. Such as, The OEM could design for remanufacturing in the product design stage in order to improve the dismantling instructions and reduce the dismantling costs of the used product. Furthermore, basing on the authorizing remanufacturing, the impact of remanufacturing on the environment, the consumer surplus and the social surplus is comparatively analysed, and the boundaries of remanufacturing being beneficial to environment is established. Also, the coordination contract is given to make supply chain of remanufacturing get the overall optimal.

Our research has some limitations and future research can be done at least in the following several avenues. Firstly, the consumer's willingness to pay (WTP) for the product is assumed to obey uniform distribution in [0,1]. Thus, obeying normal distribution is more practical and suitable to explain realistic economic activities. In addition, the authorizing remanufacturing is one of remanufacturing models, there are also two more, i.e., independent remanufacturing and outsourcing remanufacturing. So, we can comparatively analyse the advantages and disadvantages among the three model. Lastly, the coordination mechanism is only focused on the revenue of remanufacturer, the revenue of manufacturer should be considered.

Author Contributions: X.X. and C.Z. designed the study. C.Z. conducted the analysis. X.X. wrote the paper.

Funding: This research was funded by the National Natural Science Foundation of China (71702174).

Conflicts of Interest: The authors declare no conflict of interest.

\section{Abbreviations}

n Original manufacturer

$r \quad$ Remanufacturers

$c \quad$ Manufacturing costs per new product unit

$k \quad$ The recycling scale parameters of waste product

$s \quad$ The cost saving of manufacturing costs of the remanufactured product relative to the manufacturing costs per new product unit

$D$ Represents the decentralized decision-making model

C Represents the centralized decision-making model

$f \quad$ Represents the coordinated decision-making model 
$\tau^{i} \quad$ The recycling rate of used products when $i$ is in $\{D, C, f\}$

$e_{n} \quad$ The impact of the production per unit of new product on the environment

$e_{r} \quad$ The impact of the production per unit of remanufactured product on the environment $\left(e_{n}>e_{r}\right)$

$z \quad$ The costs of licensing fees per unit of remanufactured product in the case of decentralized decision-making

$p_{n} \quad$ Selling price of new product made by manufacturer when the remanufactured product is not exist on the market

$q_{n} \quad$ Quantity of new products made by manufacturer when the remanufactured product is not exist on the market

$p_{n}^{i} \quad$ Selling price of new product made by manufacturer when $i$ is in $\{D, C, f\}$

$q_{n}^{i} \quad$ Quantity of new products made by manufacturer when $i$ is in $\{D, C, f\}$

$p_{r}^{i} \quad$ Selling price of remanufactured product made by remanufacturer when $i$ is in $\{D, C, F\}$

$q_{r}^{i} \quad$ Quantity of remanufactured product made by manufacturer when $i$ is in $\{D, C, f\}$

$S^{i} \quad$ The consumer surplus of supply chain when $i$ is in $\{D, C\}$

$S^{i C} \quad$ The social surplus of supply chain when $i$ is in $\{D, C\}$

$\delta \quad$ Compared with the retail price per new product unit, the ratio of the retail price per remanufactured product unit and the retail price per new product unit perceived by consumers, also known as the relative discount, and according to the actual situation, $0 \leq \delta \leq 1$

$\pi_{n} \quad$ The profit of the manufacturer when the remanufactured product is not exist on the market

$\pi_{n}^{i} \quad$ The profit of the manufacturer when $i$ is in $\{D, C, f\}$

$\pi_{r}^{i} \quad$ The profit of remanufacturer when $i$ is in $\{D, C, f\}$

$\pi_{C} \quad$ The profit of supply chain when it is the centralized decision-making model

\section{References}

1. Liu, C.; Cai, W.; Dinolov, O.; Zhang, C.; Rao, W.; Jia, S.; Chan, F.T. Emergy based sustainability evaluation of remanufacturing machining systems. Energy 2018, 150, 670-680. [CrossRef]

2. Xu, B.-S.; Liu, S.-C.; Shi, P.-J. Contribution of remanufacturing engineering and surface engineering to cycle economy. China Surf. Eng. 2006, 19, 1-6.

3. Hashiguchi, M.S. Recycling efforts and patent rights protection in the United States and Japan. Colum. J. Envtl. L. 2008, 33, 169-195.

4. Zou, Z. Study on a Non-Independent Third Party Remanufacturing Game Model; Dalian University of Technology: Dalian, China, 2016.

5. Zou, Z.-B.; Wang, J.-J.; Deng, G.-S.; Chen, H. Third-party remanufacturing mode selection: Outsourcing or authorization? Transp. Res. Part E Logist. Transp. Rev. 2016, 87, 1-19. [CrossRef]

6. Zhu, Q.H.; Xia, X.Q.; Li, H.Y. A game model between a manufacturer and a remanufacturer based on government subsidies and patent fees. J. Syst. Eng. 2017, 32, 8-18.

7. Xiong, Z.K.; Shen, C.R.; Peng, Z.Q. Closed-loop supply chain coordination research with remanufacturing under patent protection. J. Manag. Sci. China 2011, 14, 76-85.

8. Xiong, Z.-K.; Shen, C.-R.; Peng, Z.-Q. A remanufacturing strategy for the closed-loop supply chain under patent protection. J. Ind. Eng. Eng. Manag. 2012, 26, 159-165.

9. Li, D. Study on Closed-Loop Remanufacturing Supply Chain Network Equilibrium; Southwest University of Finance and Economics: Chengdu, China, 2013.

10. Wang, J. Differential price coordination of closed-loop supply chain with remanufacturing under patent protection. Oper. Res. Manag. Sci. 2013, 22, 89-96.

11. Lind, S.; Olsson, D.; Sundin, E. Exploring inter-organizational relationships in automotive component remanufacturing. J. Remanufactur. 2014, 4, 5. [CrossRef]

12. Matsumoto, M.; Umeda, Y. An analysis of remanufacturing practices in Japan. J. Remanufactur. $2011,1,2$. [CrossRef]

13. Govindan, K.; Popiuc, M.N. Reverse supply chain coordination by revenue sharing contract: A case for the personal computers industry. Eur. J. Op. Res. 2014, 233, 326-336. [CrossRef]

14. Kaya, O. Incentive and production decisions for remanufacturing operations. Eur. J. Op. Res. 2010, 201, 442-453. [CrossRef] 
15. Yalabik, B.; Chhajed, D.; Petruzzi, N.C. Product and sales contract design in remanufacturing. Int. J. Prod. Econ. 2014, 154, 299-312. [CrossRef]

16. Wu, C.-H. Strategic and operational decisions under sales competition and collection competition for end-of-use products in remanufacturing. Int. J. Prod. Econ. 2015, 169, 11-20. [CrossRef]

17. Örsdemir, A.; Kemahlığlu-Ziya, E.; Parlaktürk, A.K. Competitive quality choice and remanufacturing. Prod. Oper. Manag. 2014, 23, 48-64. [CrossRef]

18. Jacobs, B.W.; Subramanian, R. Sharing responsibility for product recovery across the supply chain. Prod. Oper. Manag. 2012, 21, 85-100. [CrossRef]

19. Sun, H.; Liu, C.; Chen, J.; Gao, M.; Shen, X. A novel method of sustainability evaluation in machining processes. Processes 2019, 7, 275. [CrossRef]

20. Liu, C.; Cai, W.; Jia, S.; Zhang, M.; Guo, H.; Hu, L.; Jiang, Z. Emergy-based evaluation and improvement for sustainable manufacturing systems considering resource efficiency and environment performance. Energy Convers. Manag. 2018, 177, 176-189. [CrossRef]

21. Cai, W.; Liu, C.; Lai, K.H.; Li, L.; Cunha, J.; Hu, L. Energy performance certification in mechanical manufacturing industry: A review and analysis. Energy Convers. Manag. 2019, 186, 415-432. [CrossRef]

22. Cai, W.; Lai, K.H.; Liu, C.; Wei, F.; Ma, M.; Jia, S.; Jiang, Z.; Lv, L. Promoting sustainability of manufacturing industry through the lean energy-saving and emission-reduction strategy. Sci. Total Environ. 2019, 665, $23-32$. [CrossRef] [PubMed]

(C) 2019 by the authors. Licensee MDPI, Basel, Switzerland. This article is an open access article distributed under the terms and conditions of the Creative Commons Attribution (CC BY) license (http://creativecommons.org/licenses/by/4.0/). 